\title{
A randomized study of local anesthesia for pain control during intra-articular corticosteroid injection in children with arthritis
}

Jennifer E. Weiss ${ }^{1 *}$, Kathleen A. Haines ${ }^{1}$, Elizabeth C. Chalom² , Suzanne C. Li ${ }^{1}$, Gary A. Walco ${ }^{3}$, Themba L. Nyirenda ${ }^{4}$, Barbara Edelheit ${ }^{5}$ and Yukiko Kimura ${ }^{1}$

\begin{abstract}
Background: Intra-articular corticosteroid injections (IACI) are routinely used by pediatric rheumatologists in the treatment of chronic arthritis. Frequently, topical anesthetics are used to control procedural pain, but their relative efficacy has not been reported. In this study, we evaluated the level of pain associated with different anesthetic methods, Numby 900 Iontophoretic Drug Delivery System, or EMLA ${ }^{\circledast}$ cream, with or without subcutaneous buffered lidocaine (SQBL), during IACI of the knee in children with arthritis.

Methods: We conducted a prospective study of patients, ages 4 to 21 years old, followed at three pediatric rheumatology centers who were undergoing IACl of a knee joint. Patients were randomized into two treatment groups: 1) topical anesthetic only (EMLA ${ }^{\oplus}$ or Numby $\left.{ }^{\oplus}(E / N)\right)$, or 2) topical anesthetic $(E / N)$ and SQBL. Pain was assessed at baseline, during topical anesthetic placement, and following the IACI (post-procedure). The Faces Pain Scale-Revised (FPS-R), the Face, Leg, Activity, Cry, Consolability (FLACC) behavioral scale and the parental global assessment (PGA) ( $0=$ best experience, $10=$ worst experience) were determined.

Results: Sixty-three patients (44 females) with a median [IQR] age of 10.8 [IQR $=(8.2-14.4)]$ years (range 4.7-20 years) with active knee arthritis were consented. FPS-R post-procedure $(P=0.03)$, FLACC $(P=0.02)$ and PGA $(P=0.01)$ scores were significantly lower in females treated with E/N plus SQBL compared to patients treated with E/N only. Females in the E/N only group had a significant worsening of their baseline pain $(p<0.0004)$ and a greater magnitude of change in their baseline FPS-R scores $(p<0.001)$ from the procedure compared to females in the E/N plus SQBL group who had no worsening of their baseline pain. No significant change in pain level or PGA score was found among males in either treatment group. Pain scores overall were similar to the oligoarthritis patients, a more homogeneous group of patients. Both $\operatorname{EMLA}^{\circledast}(n=33)$ and Numby ${ }^{\circledast}(n=29)$ were equally well tolerated with no significant difference in median FPS-R administration scores overall.
\end{abstract}

Conclusion: Our results suggest that a topical anesthetic plus SQBL is more effective for injection pain control than topical anesthesia only. Further studies addressing pain and anxiety will help determine the optimal method of pain control for IACl.

Keywords: Juvenile idiopathic arthritis, Intra-articular injections, Pediatric rheumatology, Pain management

\footnotetext{
* Correspondence: jweiss@hackensackUMC.org

'Department of Pediatrics, Section of Rheumatology, Joseph M. Sanzari

Children's Hospital, Hackensack University Medical Center, 30 Prospect Ave.,

Hackensack, NJ 07610, USA

Full list of author information is available at the end of the article
} 


\section{Background}

Intra-articular corticosteroid injections (IACI) are one of the mainstays of treatment for patients with chronic arthritis and are part of the 2011 American College of Rheumatology recommendations for the treatment of juvenile idiopathic arthritis (JIA) [1-4]. IACI enables the physician to deliver localized treatment and may reduce the need for, or serve as an adjunct to, systemic medications. IACI may be used in patients with reactive arthritis, JIA, Lyme arthritis, and arthritis secondary to an underlying autoimmune disease such as systemic lupus erythematosus. Survey data show that $90 \%$ of pediatric rheumatologists would recommend IACI as either initial therapy or after unsuccessful therapy with non-steroidal anti-inflammatory drugs. Furthermore both parents preference and a decision analysis identified IACI as the preferred initial management of knee monoarthritis in JIA $[2,4]$.

Despite the frequent use of IACI, little attention has been paid to the pain and distress that may be associated with the procedure, and there is no established standard regarding the type of anesthesia to use for IACI. Both biological (i.e.,: age, sex) and psychological factors contribute to the fear and perception of pain and pain scores [5]. Minimizing the pain, anxiety and stress associated with the procedure is important to improve patient cooperation and to avoid unsuccessful procedural attempts [6]. Children experience pain, stress, and anxiety when undergoing IACI and it is important to treat the procedural pain both to limit suffering and to prevent lasting changes in pain systems and pain responses that may result in anticipatory anxiety and a heightened pain response with future procedures [6]. Being able to minimize pain and calm the patient will make the procedure more satisfying for all involved while ideally reducing the time it takes to perform the procedure.

Local anesthesia for IACI may include topical preparations such as $\mathrm{EMLA}^{\circ}$ cream (AstraZeneca, Inc) or LMX-4 (Ferndale Laboratories) [1, 3], lidocaine iontophoresis, ethyl chloride spray (Gebauer Co.) and subcutaneously administered lidocaine [3]. Numby 900 Iontophoretic Drug Delivery System (Iomed, Inc., Salt Lake City, UT) delivers a lidocaine HCL $2 \%$ and epinephrine 1:100,000 topical solution into the skin under the influence of electric current. Lidocaine iontophoresis has a greater depth of penetration $(8.6 \mathrm{~mm}$ after a 20 min application) [7] over a shorter period of time than $\mathrm{EMLA}^{\circ}$ (5 $\mathrm{mm}$ after a $60 \mathrm{~min}$ application) [8]. Although one study found EMLA ${ }^{\circ}$ to be ineffective for reducing the pain of IACI in children with juvenile rheumatoid arthritis, it is routinely used in clinical practice [1].

To determine the methods of local and general anesthesia currently being used by pediatric rheumatologists, a survey was conducted in 2006 of all members of the Childhood Arthritis \& Rheumatology Research Alliance (CARRA), a major research collaborative organization of pediatric rheumatologists in North America [3]. Fifty-nine percent of respondents reported using EMLA ${ }^{\circ}$, while lidocaine iontophoresis was used by $11.8 \%$ of respondents [3]. Sixty-six percent of physicians believe that giving subcutaneous lidocaine actually contributes to procedural pain. Sub-cutaneous buffered lidocaine was rarely used. Conscious sedation (CS) or general anesthesia (GA) was used by $85 \%$ of physicians, usually at the discretion of the anesthesiologist [3]. The agents most frequently used were midazolam intra-venously (39.5\%), gas (i.e.,: nitrous oxide) (30\%) and propofol (19\%) or fentanyl or vistanyl (19\%) [3]. Interestingly, only $30 \%$ of physicians use gas for IACI even though studies have shown it to be safe and effective for JIA patients undergoing IACI $[9,10]$. Ideally, successful use of a local anesthetic would reduce the number of patients treated with CS or GA minimizing risks such as respiratory depression.

The anesthetic effect of EMLA $^{\circ}$ versus lidocaine iontophoresis for IACI has not been studied, nor is it known whether the addition of subcutaneous buffered lidocaine (SQBL) is beneficial. Our objective in this open-label prospective, randomized trial was to determine the optimal method of delivering local anesthesia for IACI by comparing two treatment groups: Numby ${ }^{\circ}$ 900 Iontophoretic Drug Delivery System or EMLA ${ }^{\circ}$ cream with or without subcutaneous buffered lidocaine $(\mathrm{E} / \mathrm{N}+\mathrm{SQBL})$ or $\mathrm{E} / \mathrm{N}$ only.

\section{Method}

\section{Patients}

Patients between 4 and 21 years of age with JIA or Lyme arthritis with chronic, active arthritis of at least one knee and who were prescribed an IACI were eligible for participation in the study and enrolled between April 2006 and November 2008. Exclusion criteria included: 1) allergy to lidocaine or any ingredient used in Numby ${ }^{\circ}$ or EMLA $^{\circ}, 2$ ) use of an electrically sensitive support system (i.e., pacemakers), 3) damaged skin or signs of infection at the proposed injection site, 4) coagulopathy, or 5) inability to evaluate pain associated with the procedure.

This study was approved by the Institutional Review Boards of Hackensack University Medical Center, Hackensack, NJ, St. Barnabas Medical Center, Livingston, NJ and Connecticut Children's Medical Center, Hartford, CT. Written informed consent from parents and written informed assent when child $>9$ years old were obtained.

\section{Measures}

The Faces Pain Scale-Revised (FPS-R) is a self-report measure consisting of 6 gender-neutral faces depicting 
increasing intensity of pain that corresponds to a $0-10$ metric pain scale $(0=$ no pain, $10=$ worst pain $)$. Studies have demonstrated that the FPS-R correlates highly with other self-report pain scales and children $\geq 4$ years of age are able to use the scale [11]. Although often used for younger or non-verbal patients, a Face, Leg, Activity, Cry, and Consolability (FLACC) score was obtained in all patients, regardless of age. [12]. It is an observational pain scale that is used for young or sedated children and supplements self-report pain scales such as the FPS-R [12]. The FLACC score rates the above 5 parameters on a scale of 0-2 points for a maximum score of 10 (worst pain) [12]. A parental global assessment (PGA) was recorded based on the parent's perceptions of the patient's overall procedure experience at the completion of the procedure $(0=$ best experience, $10=$ worst experience). All three of these measures were endorsed as outcome measures for acute pain trials by the Pediatric IMMPACT group [13].

\section{Procedure}

Patients were randomized into one of four groups. Group 1 had $2.5 \mathrm{~g}$ of EMLA $^{\odot}$ applied with occlusive dressing (Tegaderm; 3 M, St. Paul, MN) for $60 \mathrm{~min}$. Group 2 had $2.5 \mathrm{ml}$ of the lidocaine hydrochloride $2 \%$ and epinephrine 1:100,000 topical solution placed on the Numby 900 electrode pad and then placed on the patient at the injection site for $20 \mathrm{~min}$. The dispersive pad was placed over a major muscle group 10-15 cm away from the drug electrode. Numby 900 was started at $2.0 \mathrm{~mA}$ for $20 \mathrm{~min}$. Group 3 had EMLA $^{\circ}$ applied as above plus an injection of SQBL (9:1 2 \% lidocaine to sodium bicarbonate). Group 4 had Numby 900 applied as above plus an injection of SQBL.

A FPS-R score was obtained from the patient at 3 time points: 1) upon arrival to the office (FPS-R baseline), 2) once the topical anesthetic was removed, before the needle was inserted (FPS-R topical anesthetic) to reflect discomfort from the anesthetic and 3) at completion of the procedure (FPS-R post-procedure) to reflect procedure pain. A FLACC score and PGA were recorded.

\section{$\mathrm{IACl}$ procedure}

Parents were present during the procedure. A child life specialist or experienced nurse was present to provide psychosocial support, distraction and to improve patients' and parents' understanding of the procedure. After the skin was sterilized with povidone-iodine and alcohol, a 21 gauge needle on a $3 \mathrm{ml}$ syringe was inserted into the joint space through a medial approach. In the SQBL group, the syringe was filled with buffered lidocaine and the periarticular space was slowly infiltrated at physician discretion. The needle was then advanced into the joint space, syringe was then replaced with a sterile empty syringe and the synovial fluid was aspirated. With the needle remaining in place, the contents of a syringe containing $1 \mathrm{mg} / \mathrm{kg}$ (maximum $100 \mathrm{mg}$ ) of triamcinolone hexacetonide was injected.

\section{Statistical analysis}

Continuous random variables were summarized as mean (standard deviation) or median (inter-quartile range) depending on whether or not the data followed the normal distribution. Categorical responses were presented as frequencies (percentages). With a two-tailed test with significance level of $5 \%$ and a defined clinically significant difference of 1.5 standard deviations on the primary outcome, pain, and power of $80 \%$, we calculated that a sample size of 72 patients (18/group) was required. Because this target was not achieved, we aggregated the four treatment groups into two treatment groups a) patients who received $\mathrm{EMLA}^{\circ}$ or $\mathrm{Numby}^{\circ}$ only $(\mathrm{E} / \mathrm{N})$ and b) patients who received EMLA ${ }^{\oplus}$ or $\mathrm{Numby}^{\oplus}$ plus SQBL $(\mathrm{E} / \mathrm{N}+\mathrm{SQBL})$. Continuous variables, age, disease duration, pain scores and global assessment were not normally distributed as indicated by the Shapiro-Wilk test. Hence, comparisons between any two groups were conducted using a Wilcoxon rank sum test. Comparisons of two groups with respect to categorical variables, gender, disease type, were performed using Chi-square test or Fisher Exact test as appropriate.

Subgroup analysis of pain scores was conducted in the cohort of oligoarthritis patients, the most common JIA subtype and a more homogeneous group of patients. Females reportedly have higher pain scores [5], so comparative analyses examined if sex effects were significant. Wilcoxon signed-rank test was used to compare the changes in FPS-R (post-procedure) FPS-R (baseline). Further, the paired differences were compared across pain management methods using Wilcoxon rank sum test taking into account patients' pain score at baseline. All statistical analyses were performed using SAS software version 9.2 (SAS Institute Inc., Cary, NC).

\section{Results}

Seventy-seven patients were approached for the study and 63 (44 girls) (Table 1) agreed to participate. Reasons for refusal were preference for topical anesthesia (13 patients) or refusal to have a child-life therapist present (1 patient). The median age of study patients was $10.8[\mathrm{IQR}=(8.2$ to 14.4$)]$ years (range $4.7-20$ years), and over $80 \%$ were Caucasian. There was no significant difference between treatment groups for disease duration or any demographic parameter (Table 1 ).

In the $\mathrm{E} / \mathrm{N}$ only group $(n=28)$, the median FPS-R baseline score was $0.0[\mathrm{IQR}=(0.0$ to 2.0$)]$ and the median FPS-R post-procedure score was higher at $3.0[\mathrm{IQR}=(2.0$ 
Table 1 Characteristics of arthritis patients receiving intra-articular corticosteroid injections

\begin{tabular}{|c|c|c|c|}
\hline Characteristics & All & $\begin{array}{l}\text { EMLA }^{\otimes} \text { or } \\
\text { Numby }\end{array}$ & $\begin{array}{l}\text { EMLA }^{\circledast} \text { or Numby }{ }^{\oplus}+ \\
\text { Buffered Subcutaneous } \\
\text { Lidocaine }^{b}\end{array}$ \\
\hline Total n (\%) & $63(100)$ & $28(44.4)$ & $35(55.6)$ \\
\hline Age $^{a}$ (years) & $10.8(8.2-14.4)$ & $11.5(8.7-13.1)$ & $10.5(8.2-14.6)$ \\
\hline Range (years) & $4.7-20$ & $4.7-17.9$ & $6.1-20.0$ \\
\hline \multicolumn{4}{|l|}{ Gender } \\
\hline Male & $19(30.2)$ & $9(32.1)$ & $10(28.6)$ \\
\hline Female & $44(69.8)$ & 19 (67.9) & $25(71.4)$ \\
\hline $\begin{array}{l}\text { Disease Duration }{ }^{\text {a }} \\
\text { (years) }\end{array}$ & $1.2(0.2-4.8)$ & $1.4(0.11-4.7)$ & $1.2(0.2-5.0)$ \\
\hline Range (years) & $0-15.6$ & $0.0-9.6$ & $0.02-15.6$ \\
\hline \multicolumn{4}{|l|}{ Disease Type } \\
\hline Oligoarthritis & $49(77.8)$ & $24(85.7)$ & $25(71.4)$ \\
\hline Polyarthritis & $7(11.1)$ & $2(7.1)$ & $5(14.2)$ \\
\hline Systemic arthritis & $1(1.6)$ & $0(0.0)$ & $1(2.9)$ \\
\hline $\begin{array}{l}\text { Enthesitis-Related } \\
\text { arthritis }\end{array}$ & $1(1.6)$ & $1(3.6)$ & $0(0.0)$ \\
\hline Psoriatic arthritis & $2(3.2)$ & $1(3.6)$ & $1(2.9)$ \\
\hline Lyme arthritis & $3(4.8)$ & $0(0.0)$ & $3(8.6)$ \\
\hline
\end{tabular}

to 6.0)]. In the E/N plus SQBL group $(n=35)$, both the median FPS-R baseline score and FPS-R post-procedure score were $2.0[\mathrm{IQR}=(0.0$ to 4.0$)]$ and $2.0[\mathrm{IQR}=(1.0$ to $4.0)$ ], respectively. A comparison between patients in the two treatment groups using the FPS-R post-procedure and FLACC scores did not reveal any significant differences. There was a significant difference in the PGA $(P=0.005)$.

Looking at all patients, there was no significant difference between treatment groups with regards to mild, moderate and severe pain. When examining the groups based on gender, the female patients in the $\mathrm{E} / \mathrm{N}$ only group had significantly worse procedure pain $(P=0.03)$ with $21 \%$ of patients having severe pain (FPS-R score 7.0-10.0) (Table 2) [14]. There was no significant difference between males.

Because it was determined that there was a significant interaction between gender and FPS-R $(P=0.02)$, FLACC $(P=0.04)$ and PGA $(P=0.005)$ scores, subsequent comparisons between treatment groups were performed within each gender (Table 2). Females in the E/N plus SQBL group had significantly lower FPS-R, FLACC and PGA post procedure scores. Overall, males $(n=19)$ in the two treatment groups did not have a significant difference in median pain or PGA scores. These findings held true even when the more homogenous group of oligoarticular JIA patients were compared (Table 3).
Table 2 Pain severity of intra-articular corticosteroid injections between treatment groups using Faces Pain Scale-Revised post-procedure scores

\begin{tabular}{|c|c|c|c|c|}
\hline Patients & Pain severity & $\begin{array}{l}\text { EMLA }^{\oplus} \text { or } \\
\text { Numby }^{\circledast} \\
(n=28)\end{array}$ & $\begin{array}{l}\text { EMLA }^{\oplus} \text { or Numby } \\
\text { Buffered Lidocaine } \\
(n=35)\end{array}$ & $P$-value \\
\hline \multirow[t]{3}{*}{ All $(n=63)$} & Mild & $14(50.0)$ & $23(65.7)$ & \\
\hline & Moderate & $10(35.7)$ & $11(31.4)$ & 0.2367 \\
\hline & Severe & $4(14.3)$ & $1(2.7)$ & \\
\hline \multicolumn{5}{|c|}{ Male $(n=19)$} \\
\hline & Mild & $7(77.8)$ & $7(70.0)$ & \\
\hline & Moderate & $2(22.2)$ & $2(20.0)$ & 1.000 \\
\hline & Severe & $0(0.0)$ & $1(10.0)$ & \\
\hline \multicolumn{5}{|c|}{ Female $(n=44)$} \\
\hline & Mild & $7(36.8)$ & $16(64.0)$ & \\
\hline & Moderate & $8(42.1)$ & $9(36.0)$ & $0.0260^{*}$ \\
\hline & Severe & $4(21.1)$ & $0(0.0)$ & \\
\hline
\end{tabular}

All data entries are counts (percentages). Pain scores: Mild: (0-3.9); Moderate $(4.0-6.9)$; Severe $(7.0-10.0) .{ }^{*} P<0.05$ was considered statistically significant

Nineteen patients (31 \%) (13 F) had a prior IACI. The Friedman rank test revealed a significant interaction between gender and prior IACI with the FPS-R $(P>0.03)$, therefore, comparisons were performed within each gender. With the exception of the FLACC scores in males, those patients who had a prior IACI did not experience worse pain compared to patients who never had a prior IACI, independent of their gender $(P>0.05)$.

Table 4 compares the change in FPS-R scores from baseline to post-procedure between treatment groups within each gender. Females in the E/N group had a significant worsening $(p=0.0004)$ of their baseline pain (pain related to their active arthritis) by 2 points compared to the females in the E/N plus SQBL group that had no worsening of their baseline pain from the procedure (Table 4, Fig. 1). Within each topical anesthetic treatment group the change in FPS-R scores from baseline to post-procedure were examined, and females in the $\mathrm{E} / \mathrm{N}$ only group had worsening of their baseline pain from the procedure $(p=0.001)$ (results not shown). No significant change in pain level was found among males either between or within treatment groups.

Both EMLA $^{\circ}(n=33)$ and Numby $(n=29)$ were equally well tolerated with no significant difference in median FPS-R administration scores overall. Adverse events were minor. In the Numby 900 group, they included: blanching $(n=17)$, redness $(n=13)$, and complaints of "tingling" $(n=14)$, "itching" $(n=7)$, "pain" $(n=6)$, and "burning" $(n=4)$. In the EMLA group, they included blanching $(n=21)$, redness $(n=9)$, and complaints of "itching" $(n=1)$. 
Table 3 Pain scores post-procedure in childhood arthritis by treatment group

\begin{tabular}{|c|c|c|c|c|c|c|}
\hline & \multicolumn{3}{|l|}{ Male $(n=19)$} & \multicolumn{3}{|l|}{ Female $(n=44)$} \\
\hline & $\begin{array}{l}\text { EMLA }^{\oplus} \text { or } \\
\text { Numby }^{\oplus}(n=9)\end{array}$ & $\begin{array}{l}\text { EMLA }^{\oplus} \text { or Numby }{ }^{\oplus}+\text { Subcutaneous } \\
\text { Buffered Lidocaine }(n=10)\end{array}$ & $P$-value & $\begin{array}{l}\mathrm{EMLA}^{\oplus} \text { or } \\
\text { Numby }^{\oplus}(n=19)\end{array}$ & $\begin{array}{l}\text { EMLA }^{\oplus} \text { or Numby }{ }^{\oplus}+\text { Subcutaneous } \\
\text { Buffered Lidocaine }(n=25)\end{array}$ & $P$-value \\
\hline \multicolumn{7}{|c|}{ All patients (63) } \\
\hline FPS-R (63) & $2.0(2.0-2.0)$ & $1.5(0.0-4.0)$ & 0.64 & $5.0(2.0-6.0)$ & $2.0(2.0-4.0)$ & $0.03^{*}$ \\
\hline FLACC (56) & $0.0(0.0-1.0)$ & $1.0(0.0-2.0)$ & 0.53 & $2.5(0.0-6.0)$ & $0.0(0.0-3.0)$ & $0.02^{*}$ \\
\hline PGA (61) & $2.0(1.0-2.0)$ & $0.5(0.0-2.0)$ & 0.37 & $2.0(1.0-5.0)$ & $0.0(0.0-2.0)$ & $0.01^{*}$ \\
\hline \multicolumn{7}{|c|}{ Oligoarthritis patients (49) } \\
\hline FPS-R (49) & $2.0(2.0-4.0)$ & $1.0(0.0-2.0)$ & 0.25 & $6.0(2.0-6.0)$ & $2.0(2.0-4.0)$ & 0.06 \\
\hline FLACC (42) & $1.0(0.0-1.0)$ & $1.0(0.0-4.0)$ & 0.74 & $3.5(0.5-7.0)$ & $0.0(0.0-2.0)$ & $0.01^{*}$ \\
\hline PGA (48) & $2.0(1.0-2.0)$ & $1.5(0.0-2.0)$ & 0.54 & $2.0(1.0-3.0)$ & $0.0(0.0-1.0)$ & $0.01^{*}$ \\
\hline
\end{tabular}

\section{Discussion}

The results of our study suggest that a combination of E/N plus SQBL along with supportive staff to aid in relaxation techniques offers improvement in pain control compared to $\mathrm{E} / \mathrm{N}$ alone for the IACI procedure. Over $40 \%$ of clinicians feel that parent and patient anxiety were issues regarding the type of anesthesia to be used for IACI, and even if the IACI should be prescribed at all [2,3]. Clinician's also viewed insufficient nursing or medical support and insufficient means for patient sedation as obstacles to IACI [2]. Our study results will reassure clinicians, patients, and their families that pain from IACI is mild in most cases and may encourage clinicians to do more injections in the office with only local anesthesia, and not use conscious sedation, if support staff such as a child life therapist or a skilled nurse is available for support of the patient and parents.

Patients in the E/N plus SQBL group had higher baseline pain scores, however, there was no statistically significant difference between the two groups. Those patients with the higher baseline pain scores may have a lower threshold for pain or greater anxiety about the upcoming procedure.
Those patients not treated with SQBL during the IACI procedure had worsening of their baseline arthritis pain in contrast to the group that received the SQBL who had no worsening of their baseline pain (Table 4). Females who only received $\mathrm{E} / \mathrm{N}$ tended to have higher median FPS-R post procedure scores and more severe procedure pain. These results are especially important since JIA overall has a female predominance, especially within the oligoarthritis sub-type.

More important than statistical significance is a minimal clinically important difference (MCID) in pain scores, in which the patient would find the procedure pain tolerable. Prior studies have shown a 2 point change in score out of 10 points (or 1 face) on the FPS to be clinically significant [15]. Our study has demonstrated a MCID in pain scores. Those patients that only received $\mathrm{E} / \mathrm{N}$ had a worsening of their baseline pain as demonstrated by an increase in their score of 2 points ( 1 face) compared to the group that received SQBL who had no worsening of their pain from the procedure. Tsze, et al. defined mild pain as a score of 0-3.9, moderate pain as a score of 4-6.9 and severe pain as a score of 7-10 [14]. If we apply this definition to our cohort, the patients in the $\mathrm{E} / \mathrm{N}$ plus $\mathrm{SQBL}$

Table 4 Comparison of Faces Pain Scale-Revised (FPS-R) scores from IACI in childhood arthritis between treatment groups by gender

\begin{tabular}{|c|c|c|c|c|c|c|}
\hline & \multicolumn{2}{|l|}{ Male $(n=19)$} & \multicolumn{4}{|c|}{ Female $(n=44)$} \\
\hline & $\begin{array}{l}\text { EMLA or Numby } \\
\text { Only }(n=9)\end{array}$ & $\begin{array}{l}\text { EMLA }^{\oplus} \text { or Numby } \\
\text { Buffered Lidocaine }(n=10)\end{array}$ & & $\begin{array}{l}\text { EMLA }^{\oplus} \text { or Numby } \\
\text { Only }(n=19)\end{array}$ & $\begin{array}{l}\text { EMLA }^{\oplus} \text { or Numby } \\
\text { Buffered Lidocaine }(n=25)\end{array}$ & \\
\hline & $\begin{array}{l}\text { Change in FPS-R } \\
\text { score }\end{array}$ & Change in FPS-R score & $P$-value & $\begin{array}{l}\text { Change in FPS-R } \\
\text { score }\end{array}$ & Change in FPS-R score & $P$-value \\
\hline All patients $(n=63)$ & $1.0(0.0-2.0)$ & $0.5(0.0-2.0)$ & 0.61 & $2.0(2.0-5.0)$ & $0.0(0.0-2.0)$ & $0.0004^{*}$ \\
\hline Oligo-arthritis $(n=49)$ & $2.0(0.0-4.0)$ & $0.0(0.0-2.0)$ & 0.16 & $2.0(2.0-5.0)$ & $0.0(-1.0-1.0)$ & $0.0006^{*}$ \\
\hline
\end{tabular}

Pain scores are reported as Median (IQR: $25^{\text {th }}-75^{\text {th }}$ percentiles); Change in FPS-R scores $=$ FPS-R post-procedure - FPS-R baseline; Comparison of the changes in FPS-R scores between treatment groups were examined using Wilcoxon rank sum test. $\mathrm{IACl}=$ intra-articular corticosteroid injection. ${ }^{*} P<0.05$ was considered statistically significant 

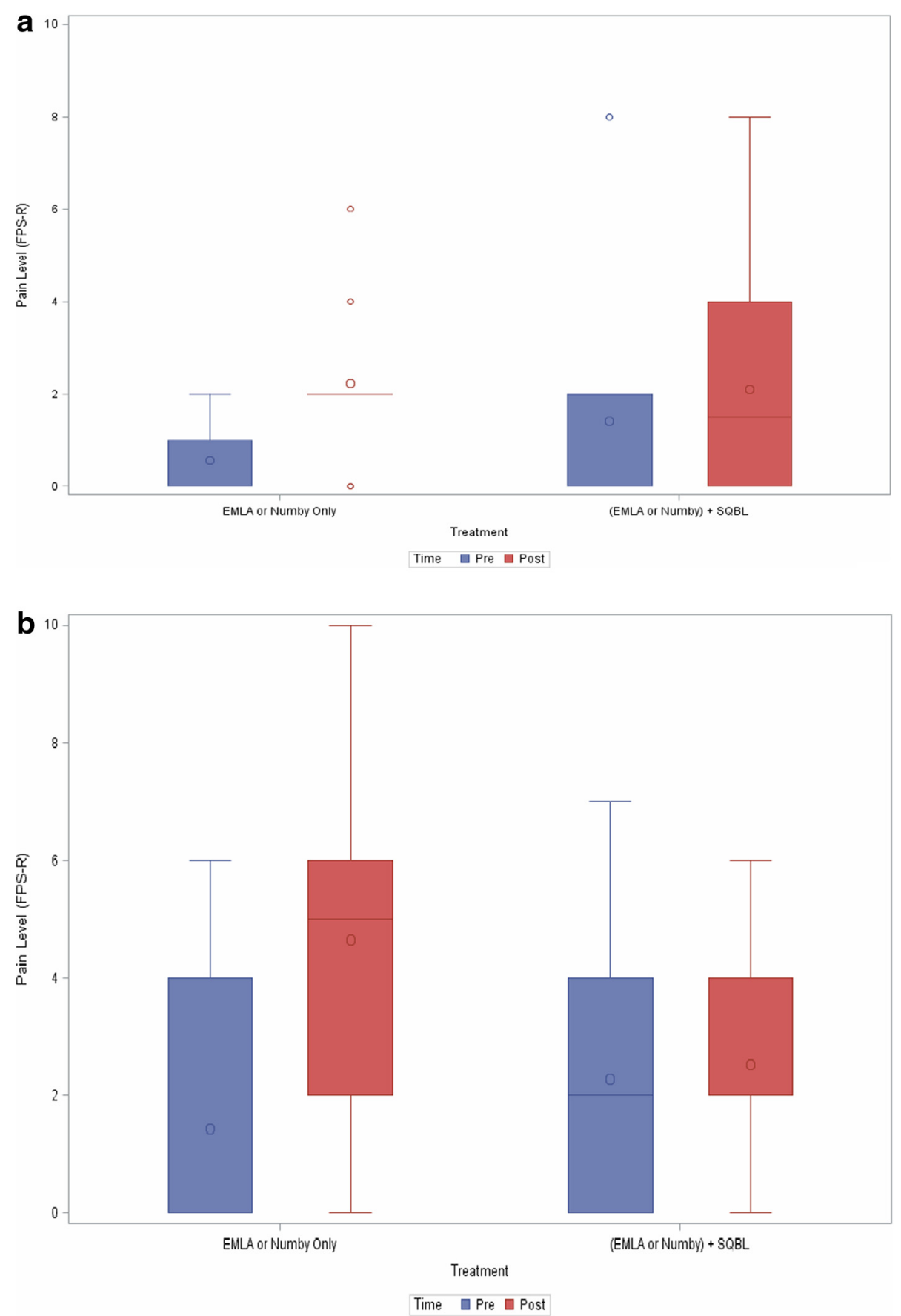

Fig. 1 a Comparison of Faces Pain Scale-Revised (FPS-R) pre- and post-procedure scores in male patients $(n=19)$ during intra-articular corticosteroid injection. b Comparison of Faces Pain Scale-Revised (FPS-R) pre- and post-procedure scores in female patients $(n=44)$ during intra-articular corticosteroid injection

group had minimal procedure pain, whereas, the FPS$\mathrm{R}$ scores were moderate (5-6) in the $\mathrm{E} / \mathrm{N}$ only group. Topical anesthetic plus SQBL resulted in excellent injection pain control as evidenced by low pain scores and a MCID in pain scores.

A contributing factor to our low pain scores may be our use of a child life therapist during the procedure.
Child life therapists play an important role in helping patients cope with anxiety and procedure pain by reassuring and distracting them and by employing relaxation techniques. Studies have shown that developmentally appropriate behavioral and cognitive pain management strategies (i.e.,: deep breathing, reassurance) are often effective in pain control $[16,17]$. Weintraub, et al. 
found that children with JIA undergoing IACI using selfadministered nitrous oxide with a medical clown in attendance prior to and during the procedure had low visual analog scores of 1 [11].

Buffering the lidocaine, which is acidic ( $\mathrm{pH} 3.5-7)$, with sodium bicarbonate and administering slowly is also an important step in reducing procedural pain as it reduces the burning sensation associated with its infiltration into skin ( $\mathrm{pH} 7.35-7.45)$ [18]. A Cochrane review published in 2010 reported that both adult and pediatric patients preferred buffered lidocaine in both parallel and cross-over trials and no adverse events were reported [18].

Both topical anesthetics were well tolerated with no significant difference in FPS-R administration scores. Blanching was the most common side effect of both agents which is to be expected due to their vasoconstrictive properties. Our patients tolerated the electric current from the lidocaine iontophoresis which was an important finding since this modality has a faster onset of action and a greater depth of penetration than EMLA $^{\circ}$ cream. A study looking at determinants of success and failure of EMLA $^{\circ}$ found that while EMLA $^{\circ}$ has proven to be safe, it seems to offer less pain control, at least when applied for $60 \mathrm{~min}$, compared to iontophoresis [19]. It is recommended that $\mathrm{EMLA}^{\circ}$ be applied for a minimum of $90 \mathrm{~min}$, preferably $120 \mathrm{~min}$ for intravenous cannulation [19]. Based on these findings, and reports by others regarding ease of use and tolerability, lidocaine iontophoresis may be the topical anesthetic of choice to use in a busy clinic setting $[3,6]$.

There were several limitations of our study including small sample size, open-label, and age of our study population. The number of patients needed to adequately power this study was not achieved. The median patient age in our study was $10.8[\mathrm{IQR}=(8.2$ to 14.4$)]$ years, so expanding the study to include a greater number of younger children would be useful to determine if our findings are applicable to children less than 5 years of age. This study was not blinded and therefore the patient may have a biased response to their treatment based on the physician's or nurse's attitudes about the anesthetic used. Normal synovium may be up to $45 \mathrm{~mm}$ thick, but inflamed synovium can be significantly thickened [20]. This can contribute to a more painful procedure, and ultrasound was not used to measure synovial thickness or as an injection guide.

\section{Conclusion}

IACI are routinely used by pediatric rheumatologists and since patients frequently need repeat injections, it is important to identify strategies that minimize pain to better ensure patient cooperation and compliance with the current and future procedures. Our results suggest that the addition of subcutaneous buffered lidocaine to a topical anesthetic is an improvement over topical agents alone, especially in females. Future studies addressing pain and anxiety around IACI are needed to establish the best practices for performing IACI.

\section{Abbreviations}

IACI: Intra-articular corticosteroid injection; EMLA: Eutectic mixture of local anesthetics; E/N: EMLA ${ }^{\oplus}$ or Numby ${ }^{\oplus}$; SQBL: Subcutaneous buffered lidocaine; JIA: Juvenile idiopathic arthritis; FPS-R: Faces pain scale - revised; FLACC: Face, legs, arms, cry, consolability; PGA: Parental global assessment; CARRA: Childhood Arthritis \& Rheumatology Research Alliance; SD: Standard deviation; IQR: Inter-quartile range; MCID: Minimal clinically important difference.

\section{Competing interests}

The authors declare that they have no competing interests.

\section{Authors' contributions}

JW conceived the study, JW and GW participated in its design, JW, KH, SL, $\mathrm{YK}, \mathrm{BC}$ and $\mathrm{BE}$ recruited participants, TN conducted and wrote the statistical analyses, JW,SL,GW, TN, BE, BC, KH, YK have all been involved in critically revising the manuscript. All authors read and approved the final manuscript.

\section{Author details}

'Department of Pediatrics, Section of Rheumatology, Joseph M. Sanzari Children's Hospital, Hackensack University Medical Center, 30 Prospect Ave., Hackensack, NJ 07610, USA. ${ }^{2}$ Saint Barnabas Medical Center, Pediatric Rheumatology, Livingston, NJ 07039, USA. ${ }^{3}$ Department of Anesthesiology \& Pain Medicine, Seattle Children's Hospital, University of Washington School of Medicine, 4800 Sand Point Way NE, Seattle, WA 98105, USA. ${ }^{4}$ Department of Research, Hackensack University Medical Center, Hackensack, NJ 07601, USA. ${ }^{5}$ Connecticut Children's Medical Center, Pediatric Rheumatology, Hartford, CT 06106, USA.

Received: 3 March 2015 Accepted: 16 August 2015

Published online: 27 August 2015

\section{References}

1. Uziel Y, Berkovitch M, Gazarian M, Koren G, Silverman ED, Schneider R, et al. Evaluation of eutectic lidocaine/prilocaine cream (EMLA ${ }^{\oplus}$ ) for steroid injection in children with juvenile rheumatoid arthritis: a double blind, randomized, placebo controlled trial. J Rheumatol. 2003;30(3):594-6.

2. Beukelman T, Guevara JP, Albert DA, Sherry DD, Burnham JM. Usage of intra-articular corticosteroid injections for the treatment of juvenile idiopathic arthritis: a survey of pediatric rheumatologists in the United States and Canada. Clin Exp Rheumatol. 2008;26(4):700-3.

3. Weiss JE, Uribe AG, Malleson PN, Kimura Y. Anesthesia for intra-articular corticosteroid injections in juvenile idiopathic arthritis: a survey of pediatric rheumatologists. Pediatr Rheumatol. 2010;8:3.

4. Beukelman T, Patkar NM, Saag KG, Tolleson-Rinehart S, Cron RQ, DeWitt EM, et al. 2011 American College of Rheumatology recommendations for the treatment of juvenile idiopathic arthritis: initiation and safety monitoring of therapeutic agents for the treatment of arthritis and systemic features. Arthritis Care Res. 2011;63(4):465-82.

5. Chambers CT, Giesbrecht K, Craig KD, Bennett SM, Huntsman E. A comparison of faces scales for the measurement of pediatric pain: children's and parents' ratings. Pain. 1999;83:25-35.

6. Walco GA. Needle pain in children: contextual factors. Pediatrics. 2008;122:S1125-9.

7. Ashburn MA. The iontophoresis of lidocaine with epinephrine. An evaluation of the depth and duration of skin anesthesia following short delivery times [abstract]. Anesthesiology. 1994;81:A391.

8. Bjerring $P$, Arendt-Nielsen L. Depth and duration of skin analgesia to needle insertion after topical application of EMLA cream. Br J Anaesth. 1990;64(2):173-7.

9. Cleary AG, Ramanan AV, Baildam E, Birch A, Sills JA, Davidson JE. Nitrous oxide analgesia during intra-articular injection for juvenile idiopathic arthritis. Arch Dis Child. 2002;86(6):416-8. 
10. Weintraub Y, Rabinowicz N, Hanuka P, Rothschild M, Kotzki S, Uziel Y. Medical clowns facilitate nitrous oxide sedation during intra-articular corticosteroid injection for juvenile idiopathic arthritis. IMAJ. 2014;16(12):771-3.

11. Hicks CL, von Baeyer CL, Spafford PA, van Korlaar I, Goodenough B. The Faces Pain Scale - Revised: toward a common metric in pediatric pain measurement. Pain. 2001:93:173-83.

12. Manworren RC, Hynan LS. Clinical validation of FLACC: preverbal patient pain scale. Pediatr Nurs. 2003;29(2):140-6.

13. McGrath PJ, Walco GA, Turk DC, Dworkin RH, Brown MT, Davidson K, et al. PedIMMPACT. J Pain. 2008;9(9):771-83.

14. Tsze DS, von Baeyer CL, Bulloch B, Dayan PS. Validation of self-report pain scales in children. Pediatrics. 2013;132:e971-9.

15. Tomlinson D, von Baeyer CL, Stinson JN, Sung L. A systematic review of faces scales for the self-report of pain intensity in children. Pediatrics. 2010;126:e1168-98.

16. Sinha M, Christopher NC, Fenn R, Reeves L. Evaluation of nonpharmacologic methods of pain and anxiety management for laceration repair in the pediatric emergency department. Pediatrics. 2006;117(4):1162-8.

17. Bandstra NF, Skinner L, Leblanc C, Chambers CT, Hollon EC, Brennan D, et al. The role of child life in pediatric pain management: a survey of child life specialists. J Pain. 2008;9(4):320-9.

18. Cepeda MS, Tzortzopoulou A, Thackrey M, Hudcova J, Arora Gandhi P, Schumann R. Adjusting the $\mathrm{pH}$ of lidocaine for reducing pain on injection (Review). Cochrane Database Syst Rev. 2010;(12):CD006581.18.

19. Lander J, Hodgins M, Nazarali S, McTavish J, Ouellette J, Friesen E. Determinants of success and failure of EMLA. Pain. 1996:64(1):89-97.

20. Smith MD. The normal synovium. Open Rheumatol J. 2011;5:100-6.

\section{Submit your next manuscript to BioMed Central and take full advantage of:}

- Convenient online submission

- Thorough peer review

- No space constraints or color figure charges

- Immediate publication on acceptance

- Inclusion in PubMed, CAS, Scopus and Google Scholar

- Research which is freely available for redistribution 